\title{
Belgian Tervuren
}

National Cancer Institute

\section{Source}

National Cancer Institute. Belgian Tervuren. NCI Thesaurus. Code C53759.

The Belgian Tervuren is a slender dog, squarely proportioned and solidly muscled, but not bulky. The erect ears are equilateral triangles. The harsh coat is medium to long, with a dense under coat and a straight, black-tipped, outer coat which produces a characteristic black overlay. Height: 22-26 inches (56-66 cm.) Weight: 60-75 pounds (27-34 kg.) 